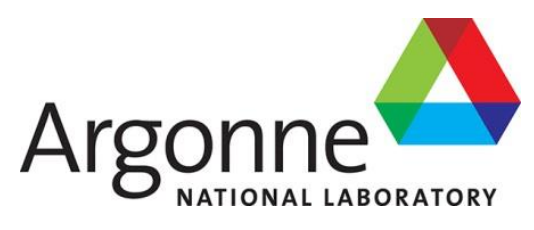

ANL-ART-128

\title{
Conceptual Design of an Improved Sodium Plugging Loop
}

Nuclear Engineering Division 


\begin{abstract}
About Argonne National Laboratory
Argonne is a U.S. Department of Energy laboratory managed by UChicago Argonne, LLC under contract DE-AC02-06CH11357. The Laboratory's main facility is outside Chicago, at 9700 South Cass Avenue, Argonne, Illinois 60439. For information about Argonne and its pioneering science and technology programs, see www.anl.gov.
\end{abstract}

\title{
DOCUMENT AVAILABILITY
}

Online Access: U.S. Department of Energy (DOE) reports produced after 1991 and a growing number of pre-1991 documents are available free via DOE's SciTech Connect (http://www.osti.gov/scitech/)

\author{
Reports not in digital format may be purchased by the public from the \\ National Technical Information Service (NTIS): \\ U.S. Department of Commerce \\ National Technical Information Service \\ 5301 Shawnee Rd \\ Alexandra, VA 22312 \\ www.ntis.gov \\ Phone: (800) 553-NTIS (6847) or (703) 605-6000 \\ Fax: (703) 605-6900 \\ Email: orders@ntis.gov \\ Reports not in digital format are available to DOE and DOE contractors from the \\ Office of Scientific and Technical Information (OSTI): \\ U.S. Department of Energy \\ Office of Scientific and Technical Information \\ P.O. Box 62 \\ Oak Ridge, TN 37831-0062 \\ www.osti.gov \\ Phone: (865) 576-8401 \\ Fax: (865) 576-5728
}

\begin{abstract}
Disclaimer
This report was prepared as an account of work sponsored by an agency of the United States Government. Neither the United States Government nor any agency thereof, nor UChicago Argonne, LLC, nor any of their employees or officers, makes any warranty, express or implied, or assumes any legal liability or responsibility for the accuracy, completeness, or usefulness of any information, apparatus, product, or process disclosed, or represents that its use would not infringe privately owned rights. Reference herein to any specific commercial product, process, or service by trade name, trademark, manufacturer, or otherwise, does not necessarily constitute or imply its endorsement, recommendation, or favoring by the United States Government or any agency thereof. The views and opinions of document authors expressed herein do not necessarily state or reflect those of the United States Government or any agency thereof, Argonne National Laboratory, or UChicago Argonne, LLC
\end{abstract}




\section{Conceptual Design of an Improved Sodium Plugging Loop}

prepared by

Yoichi Momozaki, and James. J. Sienicki

Nuclear Engineering Division, Argonne National Laboratory

April 30, 2018 


\section{ABSTRACT}

Based upon lessons learned in operating the initial sodium portion of the Sodium Plugging Phenomena Loop that itself became plugged and could not be unplugged, a set of improved design features have been identified for a new sodium loop that is less prone to inadvertent plugging. The new design features include a new sodium vessel that combines the functionalities of an expansion tank and a cold trap, increasing the loop tubing diameter/size, improving the thermal designs of the pump and flow meter, improved heater zoning, and an improved temperature distribution strategy along the loop. A new plugging loop conceptual design implementing these features has been developed. 


\section{Table of Contents}

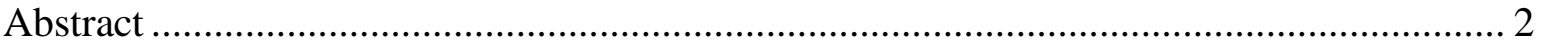

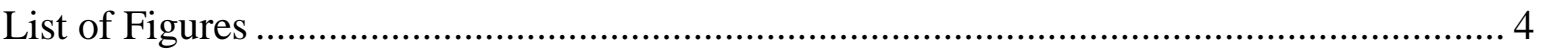

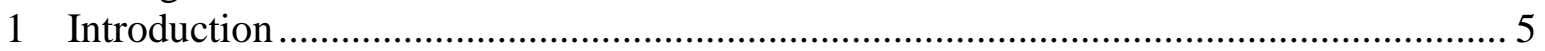

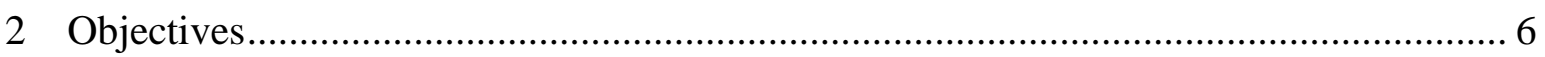

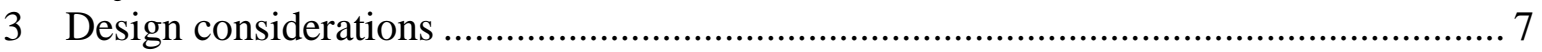

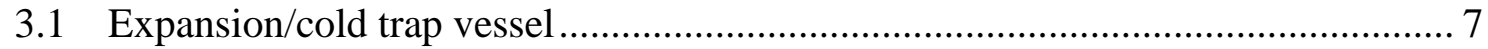

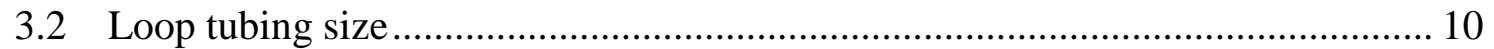

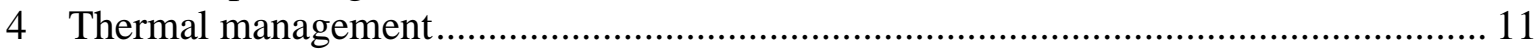

4.1 Elimination of possible cold spots ........................................................... 11

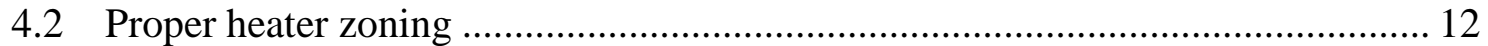

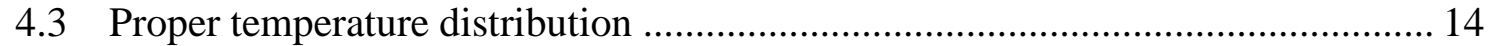

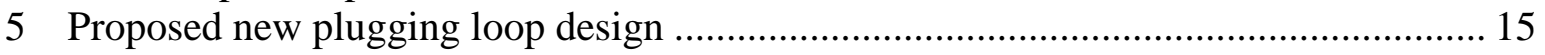

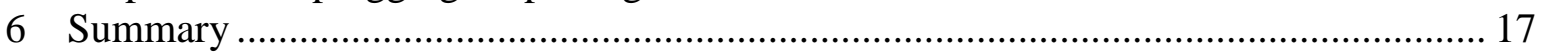

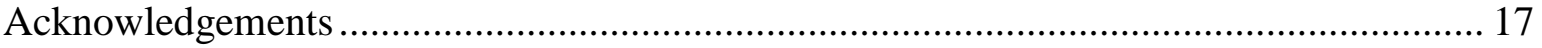

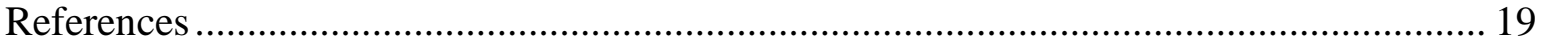




\section{LIST OF FIGURES}

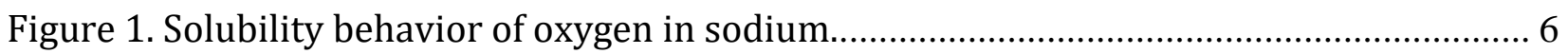

Figure 2. Current configuration of the plugging loop and the oxide transport path during oxide

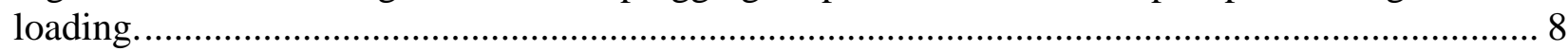

Figure 3. Proposed expansion tank/cold trap combination vessel. ................................................. 9

Figure 4. Proposed expansion tank/cold trap combination vessel with gas loading nozzle and vent

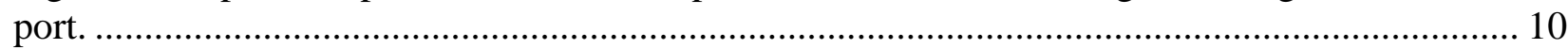

Figure 5. EM pump duct with sheath heaters for improved temperature control. ......................... 11

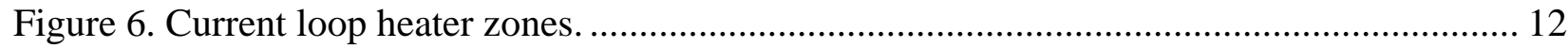

Figure 7. Example of improved heater zone arrangement for the current loop configuration....... 13

Figure 8. Current loop and key locations with identification numbers......................................... 14

Figure 9. Example of proposed temperature distribution of sodium during plugging run (See

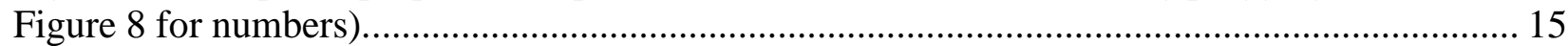

Figure 10. Example of proposed temperature distribution of sodium during unplugging run (See

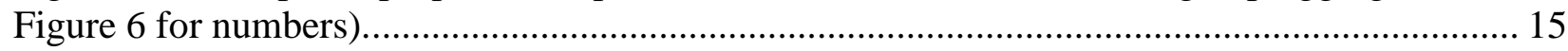

Figure 11. Proposed loop configuration and key locations with identification numbers................ 16 Figure 12. Proposed temperature distribution of sodium during plugging run (See Figure 10 for numbers)

Figure 13. Proposed temperature distribution of sodium during unplugging run (See Figure 10 for numbers). 


\section{Introduction}

Argonne National Laboratory (Argonne) has been leading the development of SodiumCooled Fast Reactors (SFRs) and supercritical carbon dioxide $\left(\mathrm{sCO}_{2}\right)$ Brayton cycle power conversion for SFRs for the U.S. Department of Energy (DOE). Argonne has been leading the development of compact diffusion-bonded sodium-to- $\mathrm{CO}_{2}$ heat exchangers for SFRs with $\mathrm{sCO}_{2}$ Brayton cycle power conversion. There is an incentive to make the coolant channels on the sodium and $\mathrm{CO}_{2}$ sides of the heat exchanger as small as possible to reduce the heat exchanger size and cost. However, there are practical limitations on how small the channels can be. On the sodium side, the channels need to be large enough to enable efficient draining of sodium from vertically oriented sodium channels. The channels must also be large enough to avoid plugging shut the heat exchanger, in the event of a break in the cover gas system allowing air to enter the Argon cover gas in an Intermediate Heat Transport System (IHTS) sodium loop with failure or shutdown of the intermediate sodium cold trap circuit. In particular, oxygen would be transported to the Argon cover gas above the sodium free surface inside of the expansion tank/vessel, where it would dissolve into the liquid sodium. The solubility of oxygen in sodium decreases with temperature to essentially zero at the freezing temperature. This is the basis for cold trapping as an effective means to purify sodium from oxygen impurities. The solubility increases exponentially with inverse absolute temperature as shown in Figure 1.

As more oxygen dissolves into the intermediate sodium at the free surface, the oxygen concentration will eventually exceed the solubility limit at the cold end of the sodium-to- $\mathrm{CO}_{2}$ heat exchanger. Oxygen will begin to precipitate out of solution as sodium oxide $\left(\mathrm{Na}_{2} \mathrm{O}\right)$ upon the stainless steel walls of the sodium channels at the cold end. This process must be stopped before the sodium oxide deposits plug shut the sodium channels. Sodium oxide has a high melting temperature of about $1350{ }^{\circ} \mathrm{C}$. It is not practical to melt out by heating an oxide plug that has formed due to the high oxide melting temperature. It might be possible to dissolve out a complete plug by washing it with relatively pure liquid sodium but such a process with a plug that completely blocks a channel must rely only on diffusive oxygen transport into the sodium mass adjacent to it. Because dissolution is limited by the diffusivity of oxygen in sodium, this process is very slow. Unplugging a completely plugged channel could take weeks or months. Thus, it isn't practical. It is therefore essential that the sodium channels be large enough such that the sodium oxide deposition and plug growth process takes long enough that the ongoing plugging of the sodium channels can be detected, and the intermediate sodium loop shut down and drained of liquid sodium to stop the plugging process before the sodium channels have become significantly occluded. If significant flow over a deposit is still possible, then the deposit might be dissolved away through forced convection mass transfer by flowing pure sodium over it.

The Sodium Plugging Phenomena Loop was constructed at Argonne to measure the time for sodium channels to plug due to precipitation of dissolved oxygen under conditions prototypical of a sodium-to- $\mathrm{CO}_{2}$ heat exchanger, and to conduct fundamental investigations of the phenomena involved in sodium oxide deposit growth and dissolution. It was used for initial investigations of sodium plugging phenomena as discussed in References [1] through [4]. The facility is actually two loops; a closed sodium loop with a test section simulating sodium channels inside of a sodiuimto- $\mathrm{CO}_{2}$ heat exchanger and an open air loop that cools the sodium as it flows through the test section to simulate the decreasing temperature along the sodium flowpath inside of a heat exchanger. 
Unfortunately, the sodium portion of the facility became inadvertently plugged itself. Efforts to unplug it were unsuccessful. It has been decided to reconstruct the sodium portion with a new sodium loop design that is less susceptible to inadvertent plugging. This report presents the current status of a conceptual design for the new sodium loop.

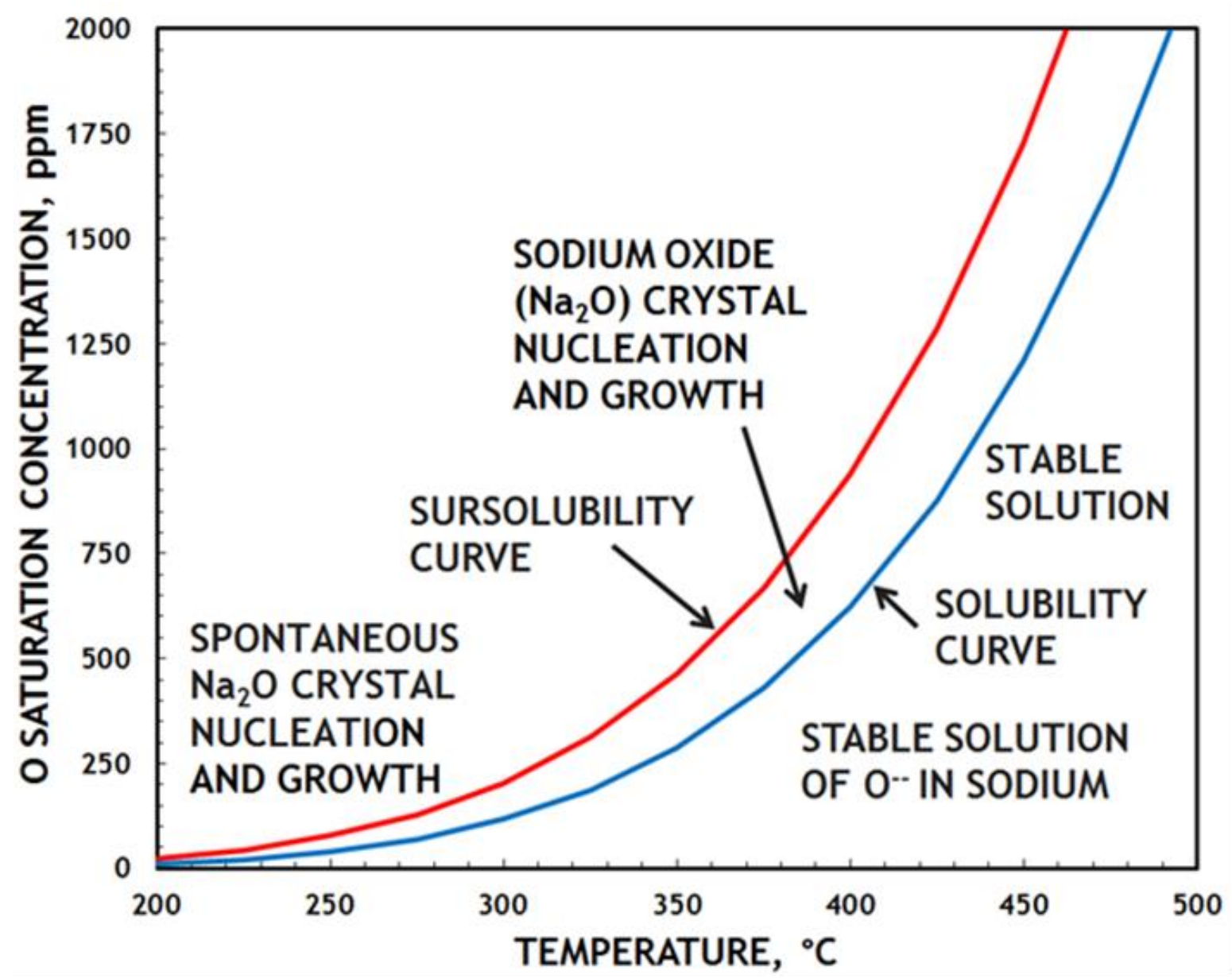

Figure 1. Solubility behavior of oxygen in sodium.

\section{Objectives}

The objective of this report is to present design considerations and suggested operating strategies to properly conduct plugging tests with aggressive operating conditions (i.e., high dissolved oxygen concentrations in sodium). Especially important ones are:

1) A conceptual design of a new expansion/cold trap vessel to load and store the excess oxides in the system without causing any uncontrolled plugging; and 
2) An additional thermal management approach to eliminate potential cold spots and to establish proper temperature distributions to safely circulate the sodium with high oxide concentration during various plugging experiments with varying cold trap and test section temperatures.

Also a new conceptual design of the loop is proposed.

\section{Design considerations}

\subsection{Expansion/cold trap vessel}

The current plugging loop uses a cold trap that is a small stainless steel container with one sodium inlet and one sodium outlet. The cold trap is not specifically designed to maintain free sodium surfaces in it and has no access ports to minimize the risk of sodium leak, except a port to insert a multi-junction thermocouple (TC) probe to monitor the distribution of the sodium temperature inside the cold trap. The cold trap is generally the coldest part of the loop and serves as an oxide-storage vessel. A separate expansion tank is located at the top of the loop where a free sodium surface is maintained to accommodate the expansion/contraction of the sodium. There are several ports at the top of the expansion tank above the free sodium surface where the ports will not submerge in the sodium such that the potential for a sodium leak is considered practically nonexistent. These ports include a TC port, a cover gas port, and a loading port. See Figure 2. 


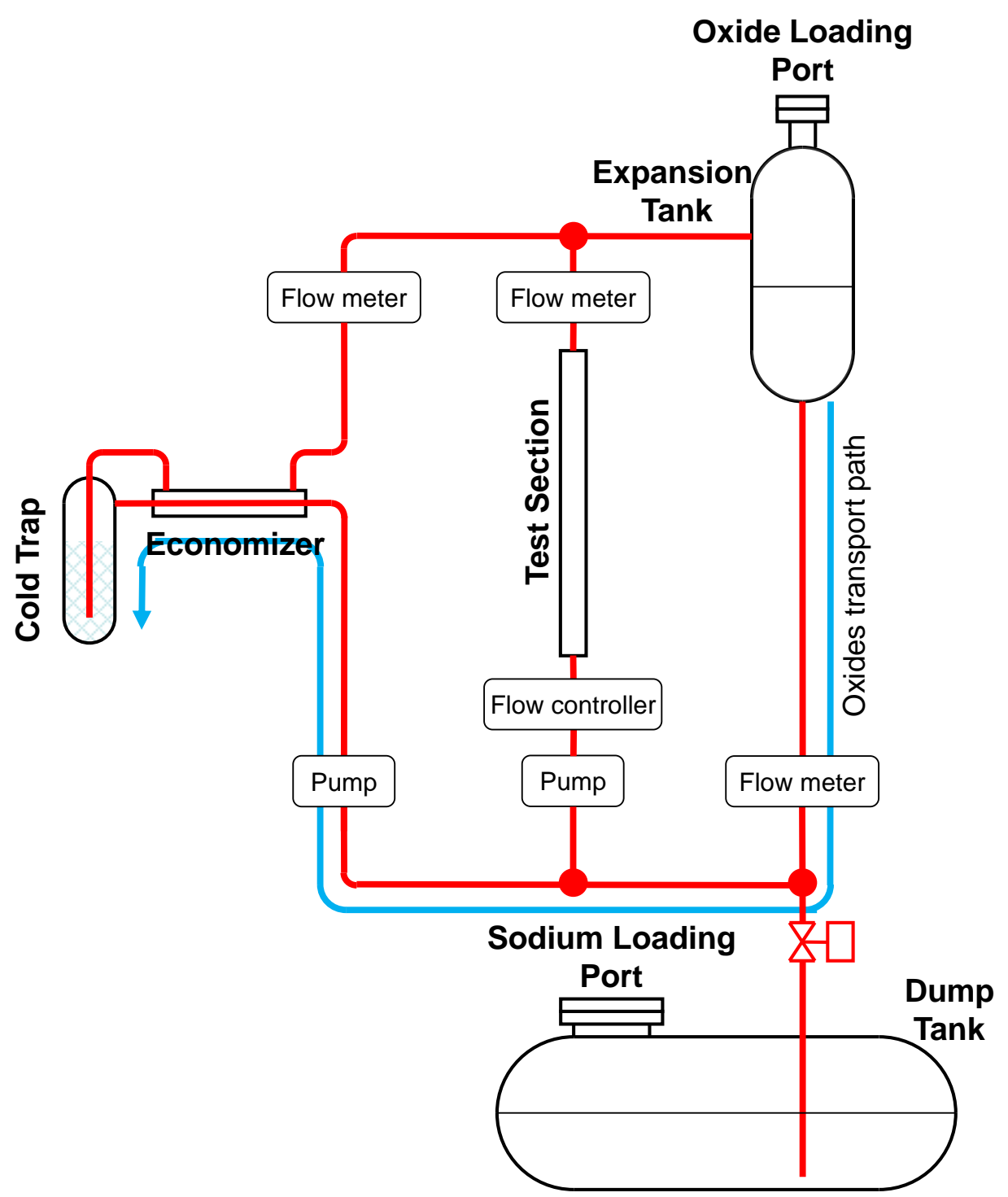

Figure 2. Current configuration of the plugging loop and the oxide transport path during oxide loading.

In this configuration, an amount of sodium oxide is added at the expansion tank to the loop to increase the oxygen content in the sodium. The oxide dissolves in the molten sodium at a similar temperature as the expansion tank and has to be transferred to the cold trap by the molten sodium through the loop (indicated by the blue arrow in the figure). Some of the solid oxides may also be carried with the flowing sodium. Obviously, the dissolved oxygen concentration in the sodium cannot be well controlled. The presence of an oxygen saturation concentration that is higher than at the cold trap temperature potentially can lead to unexpected plugging of the loop.

To avoid flowing the sodium with an uncontrolled concentration of oxygen through the loop, a vessel that combines the functions of the cold trap and the expansion tank is proposed as shown in Figure 3. The container consists of a sodium flow passage with a pack of mesh for oxide precipitation as a cold trap and an open space in it to serve it as an expansion tank. The presence 
of the free surface in the container permits the installation of a valve for oxide loading. This container allows loading of the oxide directly in the cold trap so that the sodium containing an uncontrolled amount of oxygen does not flow outside of the container.

\section{Oxide Loading \\ Port}

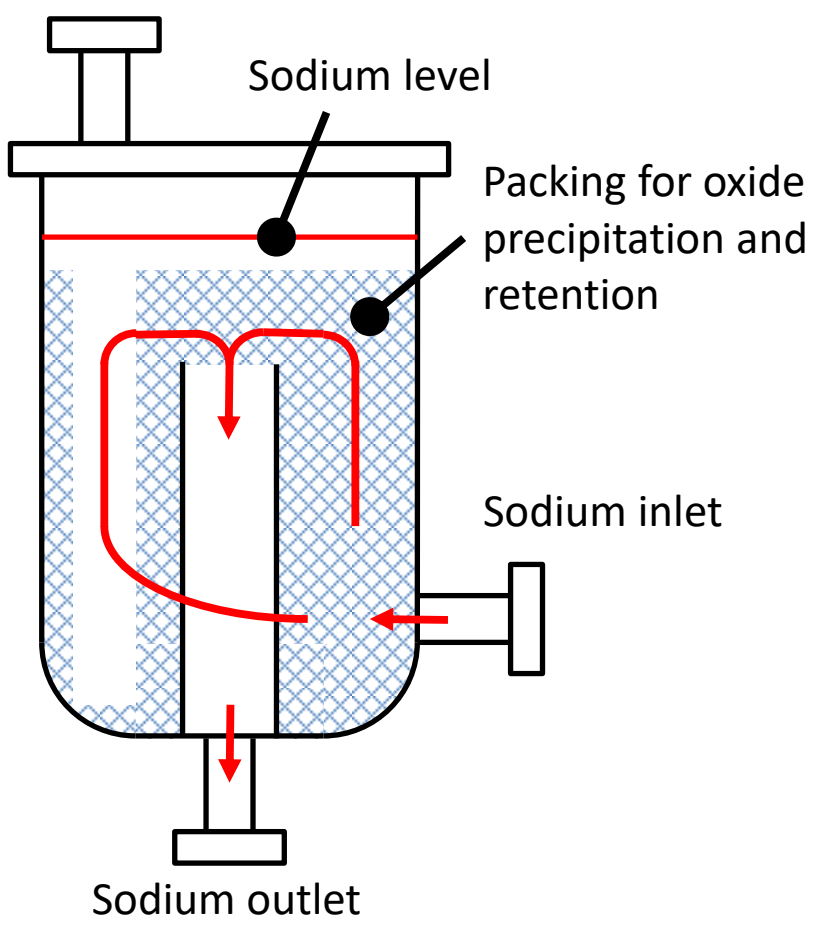

Figure 3. Proposed expansion tank/cold trap combination vessel.

The oxygen may be added as a gas or as solid sodium oxides. For the gas injection method, the oxygen must be mixed with a carrier gas, for example, argon and this gas mixture (such a gas mixture can be readily purchased) will be introduced into the container as shown in Figure 4. Handling pure oxygen is a technically difficult task and injecting the pure oxygen into molten sodium would probably induce an explosive reaction between the oxygen and the sodium. The advantage of this method is that the rate of oxide addition can be finely controlled. However, removal of the excess carrier gas may be a problem of this approach. For example, to load 1 gram of oxygen $(0.03$ mole $)$ into the loop, approximately 0.7 liters of pure oxygen at the standard temperature and pressure (STP) is needed. According to a paper [1][5], molten sodium ignites in an atmosphere with the oxygen concentration of around a few percent. We may use the oxygen concentration below $1 \%$ to make sure any ignition will not take place in the loop while injecting the gas for safety. This dilution of the oxygen translates to 70 liters of the gas mixture at STP needs to go through the loop per 1 gram of oxygen addition and by definition $99 \%$ of the carrier gas needs to be exhausted from the loop. The excess carrier gas may contain some sodium vapor and/or mist which need to be properly treated before it vents to the atmosphere. 


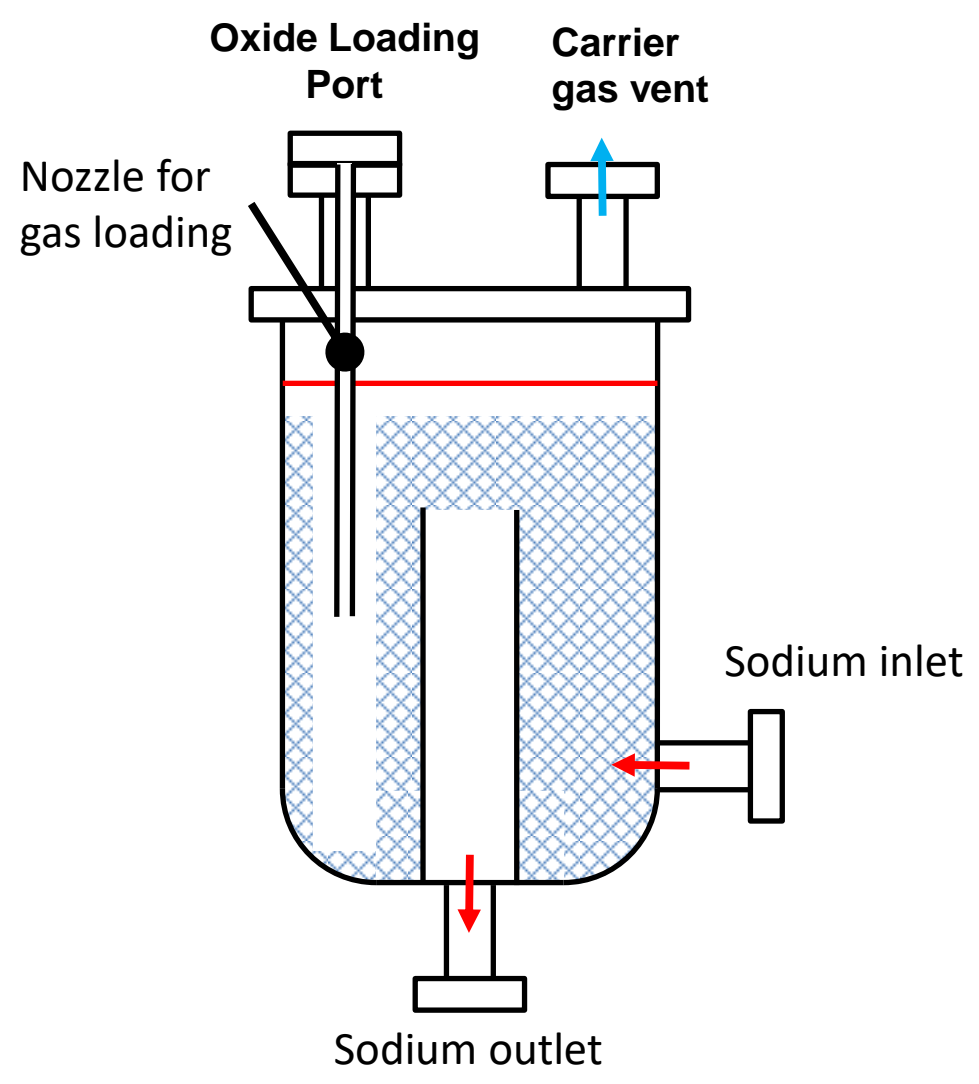

Figure 4. Proposed expansion tank/cold trap combination vessel with gas loading nozzle and vent port.

For the solid oxide loading alternative, $\mathrm{Na}_{2} \mathrm{O}$ may be used to add oxygen into the loop, which translates to 3.9 grams of $\mathrm{Na}_{2} \mathrm{O}$ is needed to add 1 gram of oxygen. The density of the oxide is about $2.3 \mathrm{~g} / \mathrm{cm}^{3}$. Although this method will not require any release of gas from the loop, it would be more difficult to control the rate of oxygen addition to the system relative to the gas loading method. In addition, it would require more complex hardware to avoid any contamination from air if the oxide needs to be safely loaded into the molten sodium. It is because when the vessel is hot (the sodium in it is molten), the hot cover gas in the vessel tends to rise and flows out through the loading port. On the other hand, the relatively cooler air in the atmosphere tends to sink into the vessel through the port. When the vessel is at room temperature, since the argon cover gas is denser than air at the same temperature, the cover gas tends to stay inside the vessel while the loading port is opened. Mixing of the gas and the air due to thermally driven natural convection is not expected to occur. In the current plugging loop, the oxide can only be added to the frozen sodium in the expansion tank at room temperature to minimize the contamination of the sodium. Thus, when the sodium is heated, the sodium will become locally saturated and the oxide cannot be fully dissolved until a sufficiently elevated sodium temperature is attained.

\subsection{Loop tubing size}


The current plugging loop uses $1 / 2$ inch tubing for the most of the parts and since the loop experienced unexpected plugging after a large amount of oxide had been added, the tubing size may have to be increased for more stable circulation of the sodium with a high concentration of oxygen in it. A 3/4 inch tubing size is currently considered sufficient to decrease the risk of sodium plugging inside of the tubing.

\section{Thermal management}

\subsection{Elimination of possible cold spots}

The present electromagnetic (EM) pumps and flowmeters use permanent magnet dipoles with a small magnetic gap to maximize the magnetic field strength in the dipoles. The small gap made it difficult to thermally insulate and/or to electrically heat the sodium tubing that goes through the gap. Also the relatively large copper electrodes attached to the sodium tubing in the EM pumps are prone to excessively dissipate away heat. The new magnetic dipole design should consider not only the strength of the magnetic field in the gap, but also ease of implementing effective thermal insulation and/or electrical heating. Also, the new design for the EM pump and flow meter should consider not only minimizing the electrical resistance of the electrodes, but also minimizing the heat losses from the electrodes or even implementing an actively heated pump duct and/or electrodes (for example, see Figure 5).

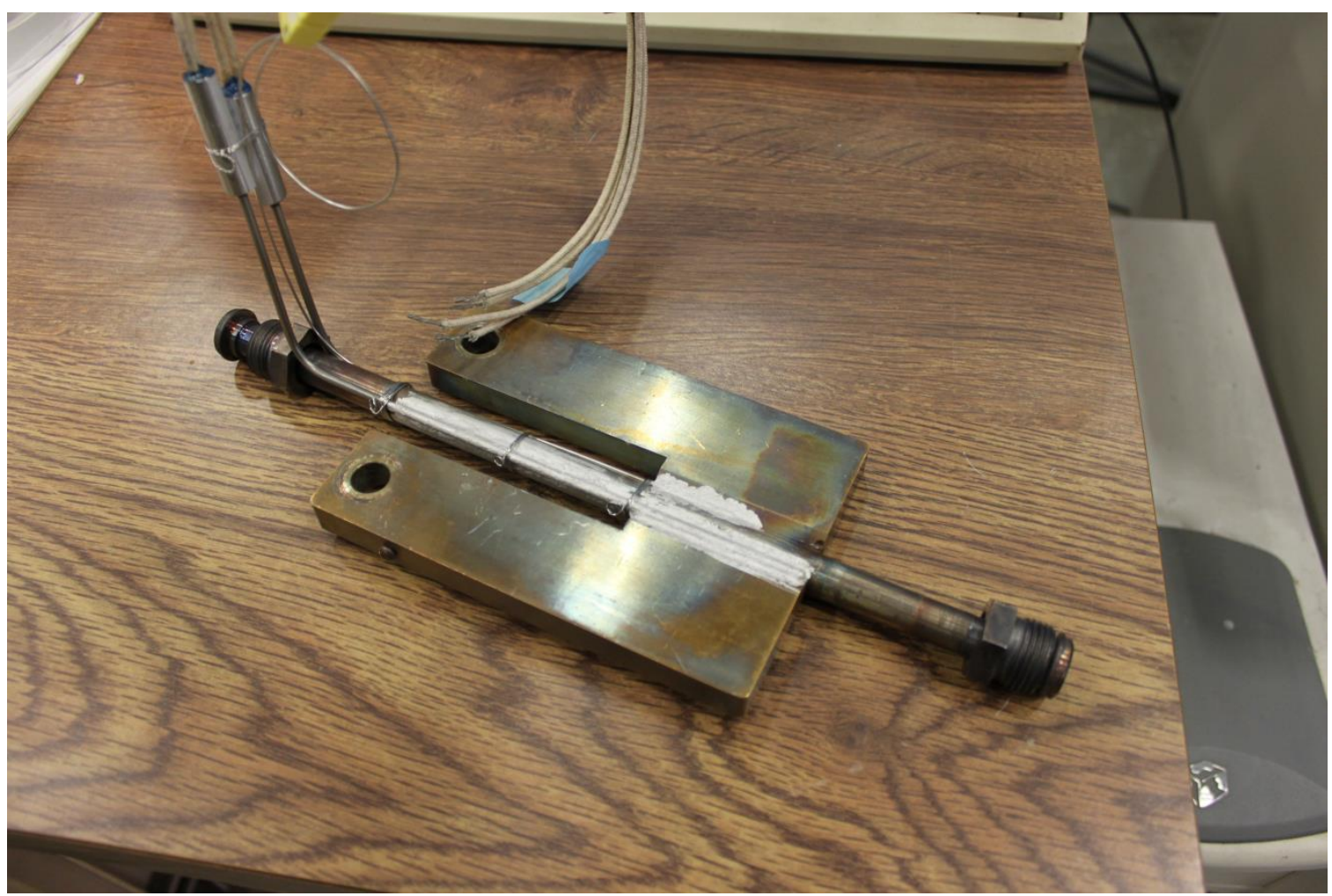

Figure 5. EM pump duct with sheath heaters for improved temperature control. 


\subsection{Proper heater zoning}

There are seven zones in the loop (see Figure 6). Each heater zone is represented by a color band in the figure. These seven zones allow independent control of each component in the loop. The present heater zoning is sufficient to keep the loop hot enough to circulate the molten sodium while independently controlling the temperature of each component in the loop, but is not apparently adequate to reliably circulate sodium with a high oxygen concentration.

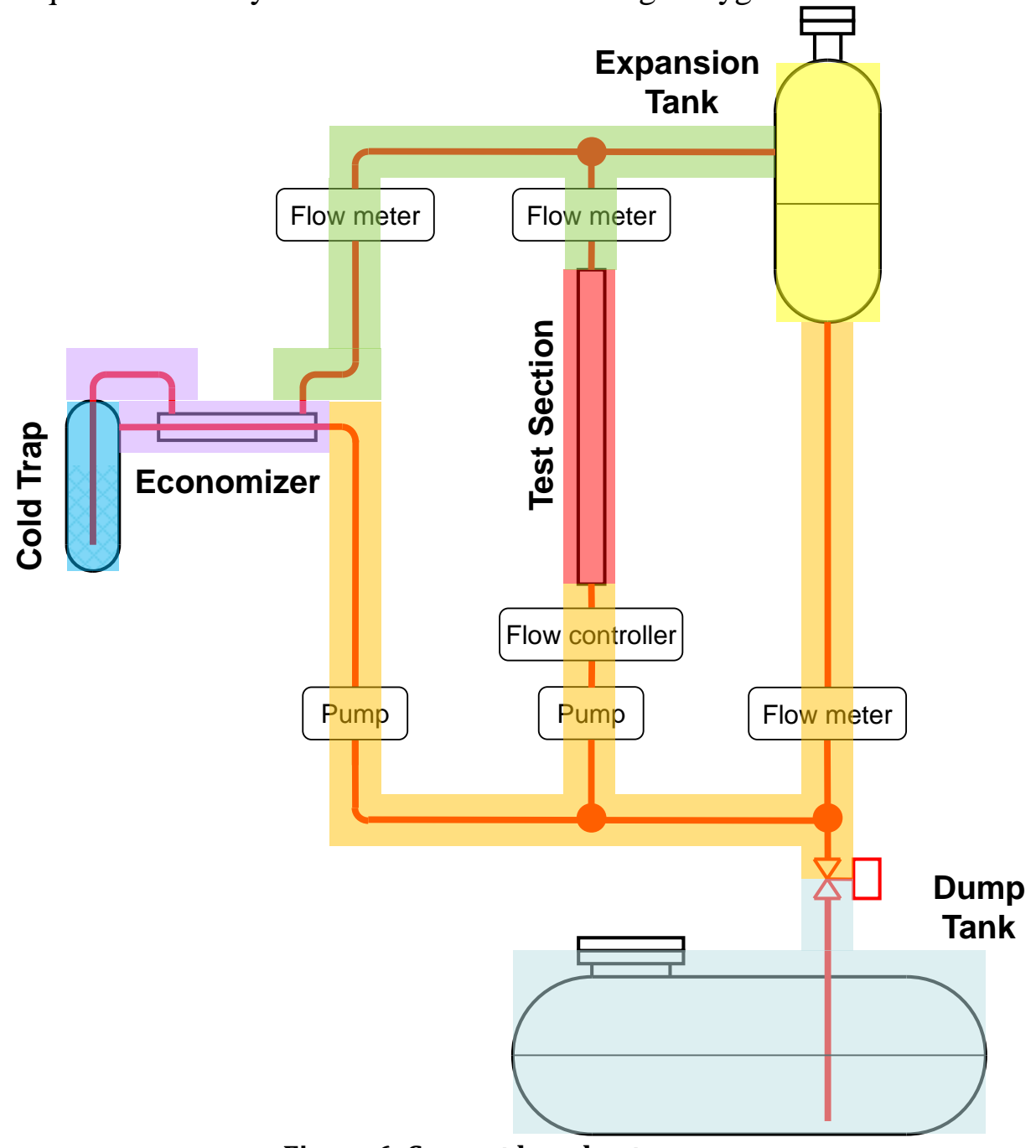

Figure 6. Current loop heater zones.

This arrangement does not allow precise and independent controlling of the temperature of the sodium itself in each flow path. For reliable circulation of the sodium with high oxygen concentration, it is important to keep the sodium temperature above the coldest temperature within the loop to prevent any oxide precipitation from happening, assuming that the concentration of the oxygen in the sodium is always controlled by the coldest temperature. Usually, the coldest temperature in the loop is the cold trap temperature. This may not be the case during oxygen 
loading or while unplugging the test section after a plugging test. A better approach is shown in Figure 7.

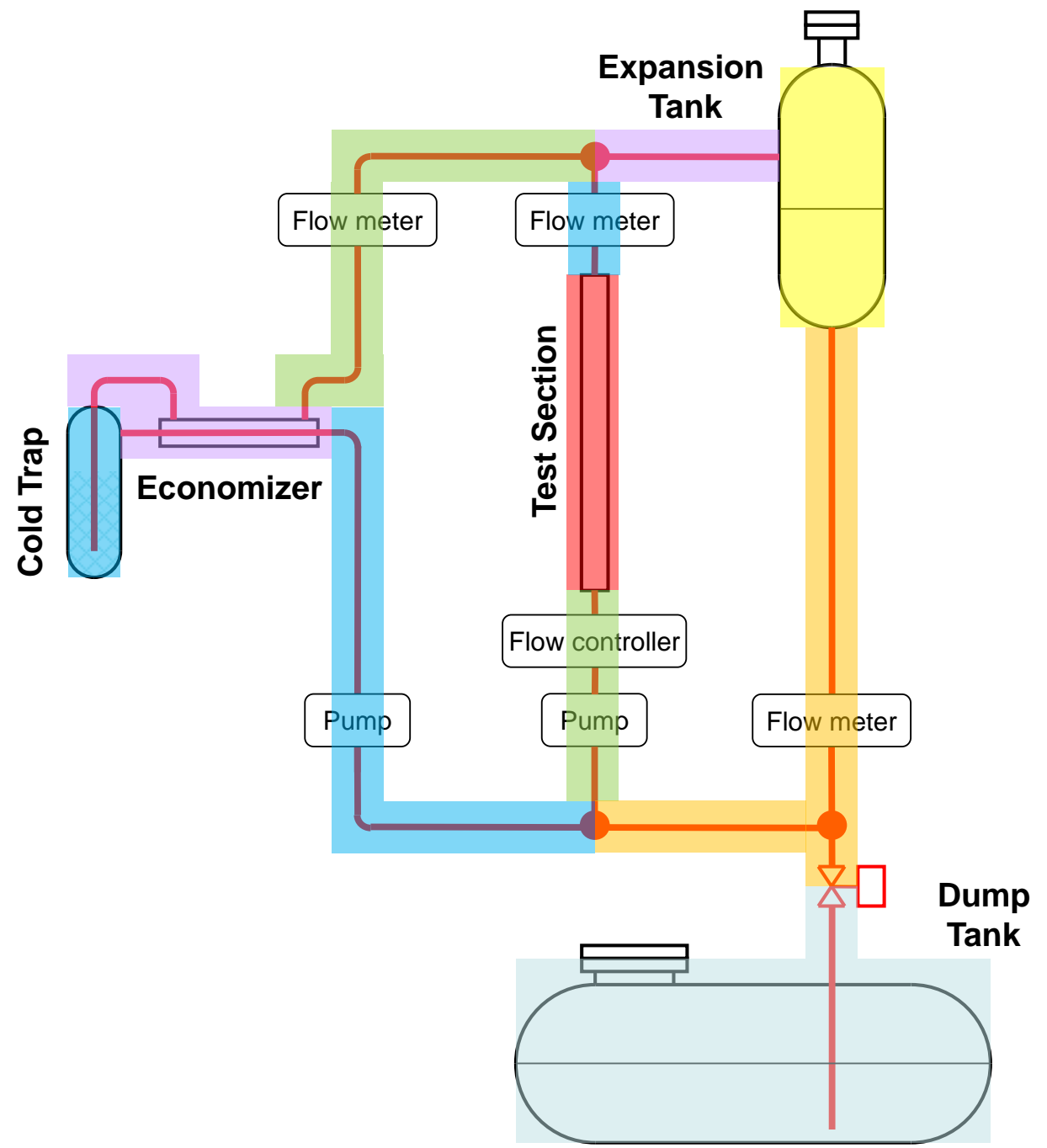

Figure 7. Example of improved heater zone arrangement for the current loop configuration. 


\subsection{Proper temperature distribution}

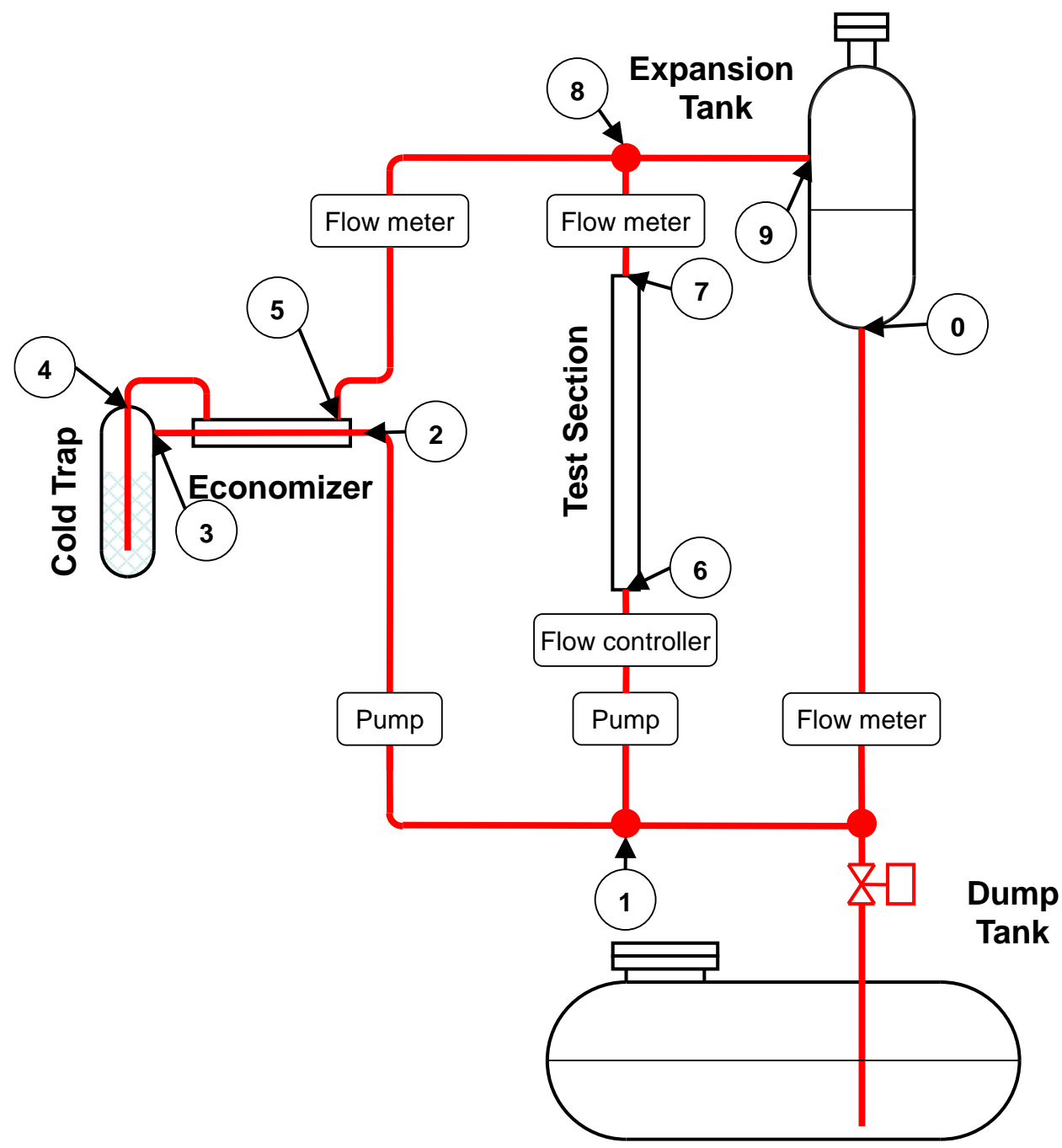

Figure 8. Current loop and key locations with identification numbers.

A better approach to control the temperature of the loop may be to keep not only the temperature of the loop and the sodium in it above the temperature of a component where the oxides may exist, but also to keep a positive temperature gradient along the sodium flow direction such that the sodium temperature flowing away from the oxides is always increasing. A negative temperature gradient should only be present within a component where intentional oxides precipitation takes place and should be eliminated as much as possible elsewhere. A proposed temperature distribution during a plugging run is shown in Figure 9. The numbers indicate various locations along the loop. The dashed line is the temperature distribution along the test section. The coldest spot in the solid line corresponds to the coldest spot in the cold trap (between " 3 " and " 4 ") and the coldest spot in the dashed line corresponds to the coldest spot in the test section (between "6" and "7"). Note that during a plugging run, the coldest spot in the test section is lower than the coldest spot in the cold trap. 


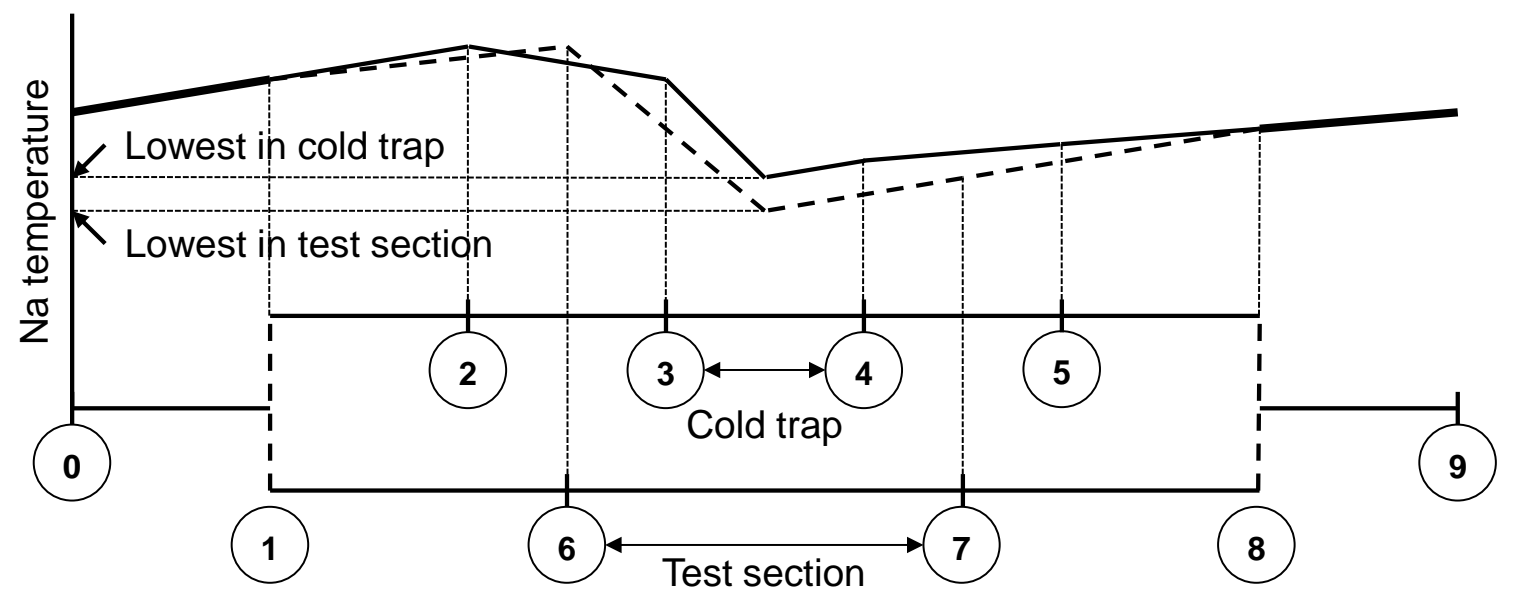

Figure 9. Example of proposed temperature distribution of sodium during plugging run (See Figure 8 for numbers).

A proposed temperature distribution during an unplugging run is also shown in Figure 10. The temperature of the coldest spot in the test section is increased above the coldest spot in the cold trap. If the test section temperature is raised too high for facilitating the dissolution of the sodium oxides, the sodium between " 2 " and " 3 " may become supersaturated with the oxygen, potentially plugging the sodium line before the cold trap.

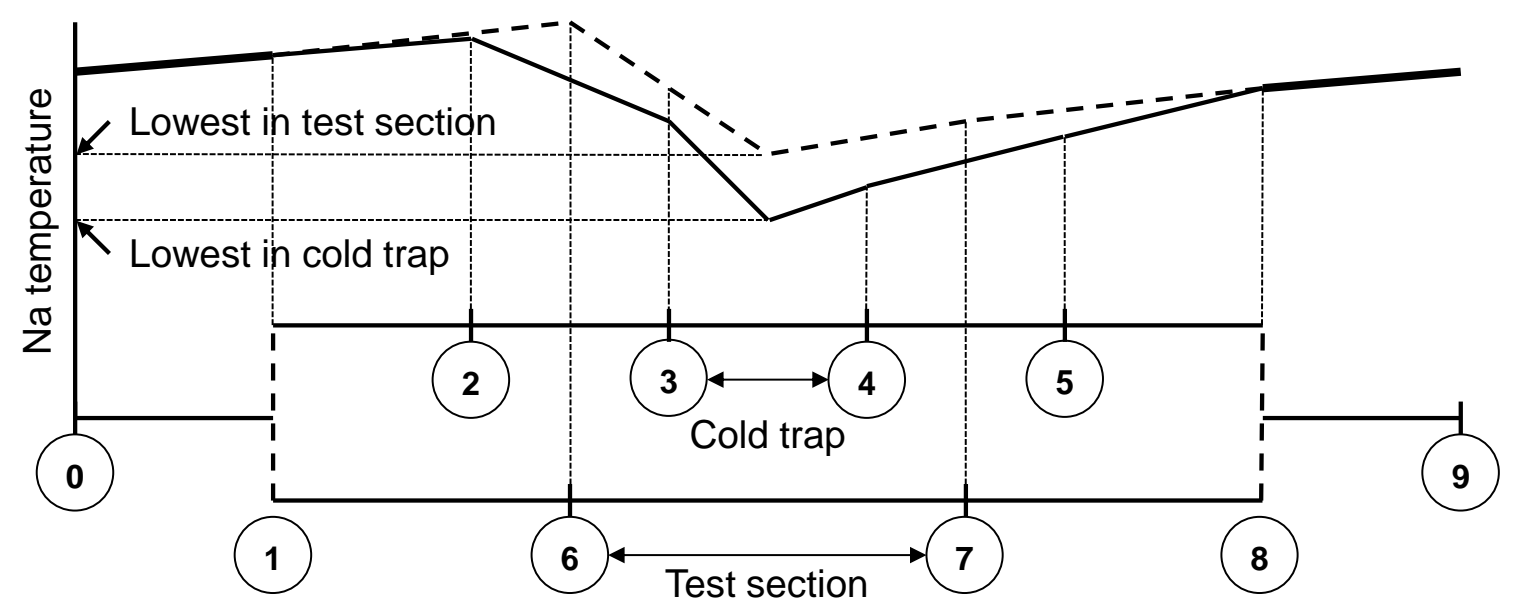

Figure 10. Example of proposed temperature distribution of sodium during unplugging run (See Figure 6 for numbers).

\section{Proposed new plugging loop design}

A proposed new plugging loop configuration is shown in Figure 11. The combined expansion and cold trap tank is employed. The loop piping size should be greater than $1 / 2$ inch tubing in size. The pump and the flow meter should be equipped with additional heaters to maintain them at their optimum temperatures. The bypass circuit is eliminated to simplify the topology of 
the loop to help establish the proper temperature distributions during a variety of running conditions.

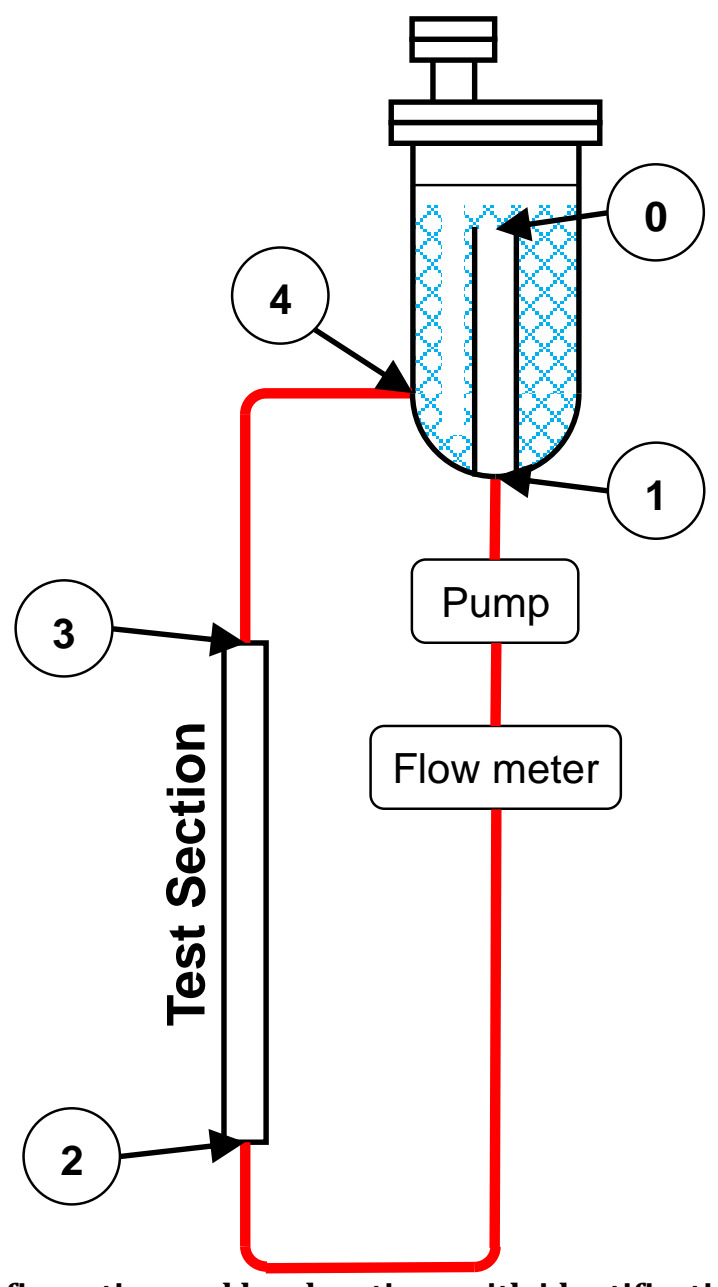

Figure 11. Proposed loop configuration and key locations with identification numbers.

The heater system should be designed to produce the suggested temperature distributions for plugging and unplugging. The suggested temperature distributions are shown in Figure 12 and Figure 13. As these temperature distributions indicate, the piping part of the loop should be equipped with heaters that have a larger capacity than to just maintain the temperature of the sodium. These heaters need to be aggressively able to increase the temperature of the sodium to form the proper temperature gradient. Similarly, both the cooling capability and heating capability of the expansion/cold trap tank and the test section need to be large to produce large temperature changes within the components. For example, it may be advisable that an additional rod heater be inserted at the center of the expansion/cold trap tank to aggressively heat up the sodium temperature. 


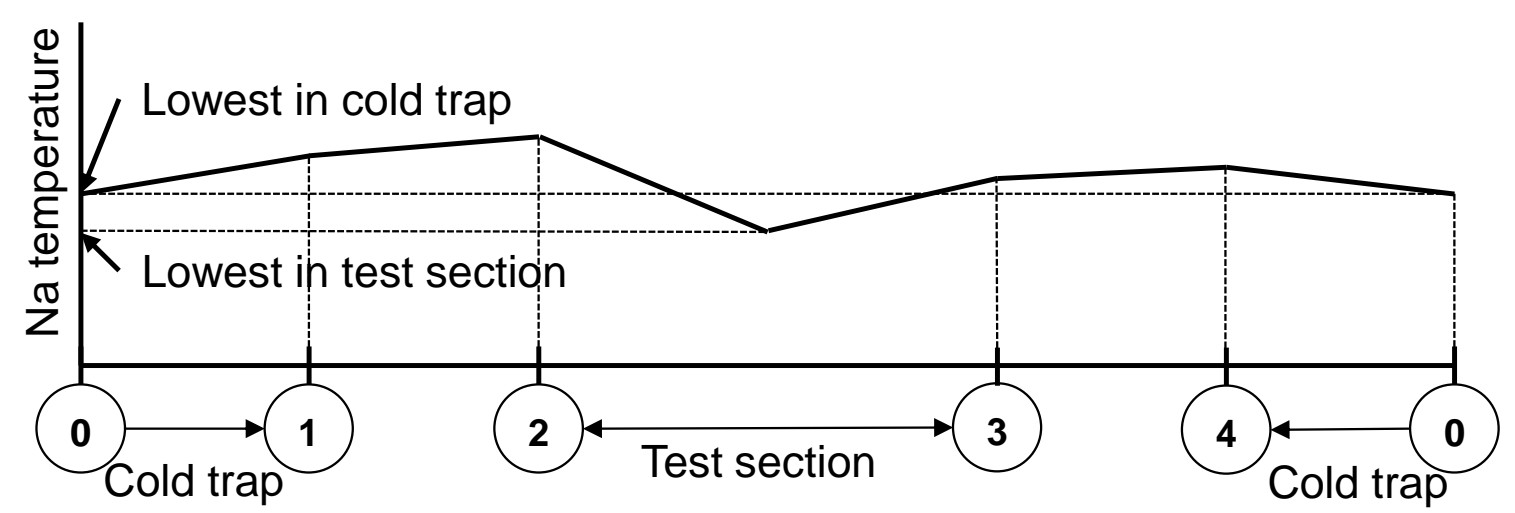

Figure 12. Proposed temperature distribution of sodium during plugging run (See Figure 11 for numbers).

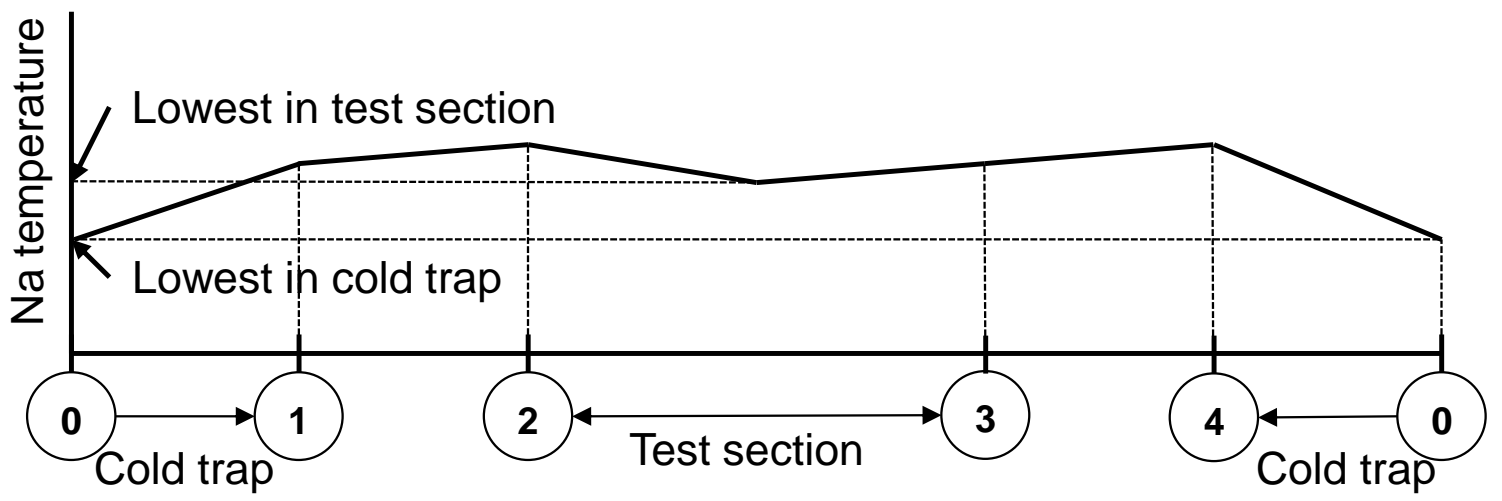

Figure 13. Proposed temperature distribution of sodium during unplugging run (See Figure 11 for numbers).

\section{Summary}

Based upon lessons learned in operating the initial sodium portion of the Sodium Plugging Phenomena Loop that itself became plugged and could not be unplugged, a set of improved design features have been identified for a new sodium loop that is less prone to inadvertent plugging. The new design features include a new sodium vessel that combines the functionalities of an expansion tank and a cold trap, increasing the loop tubing diameter/size, improving the thermal designs of the pump and flow meter, improved heater zoning, and an improved temperature distribution strategy along the loop. A new plugging loop conceptual design implementing these features has been developed.

\section{Acknowledgements}

Argonne National Laboratory's work was supported by the U. S. Department of Energy Nuclear Technology Research and Development Program under Prime Contract No. DE-AC0206CH11357 between the U.S. Department of Energy and UChicago Argonne, LLC. The work 
presented here was carried out under the Fast Reactors area of the Program. The authors are grateful to Chris Grandy (Argonne/Nuclear Engineering), the Technical Area Lead, Bob Hill (Argonne/Nuclear Engineering), the National Technical Director, as well as Alice Caponiti and Tom Sowinski (U.S. DOE), Headquarters Program Managers for the Project. 


\section{References}

[1] Momozaki, Y., Cho, D. H., Sienicki, J. J., and Moisseytsev, A., "Experimental Investigations on Sodium Plugging in Narrow Flow Channels," Nuclear Technology, Vol. 171, p. 153-160, 2010.

[2] Sienicki, J. J., "Unified Analysis of Sodium Oxide Deposit Growth and Sodium Plugging," Paper 6463, Advances in Thermal Hydraulics Meeting (ATH '12), San Diego, November 11-15, 2012.

[3] Sienicki, J. J., "Modeling Sodium Oxide Deposit Growth and Sodium Plugging,” IAEACN-199/181, International Conference on Fast Reactors and Related Fuel Cycles: Safe Technologies and Sustainable Scenarios (FR13), Paris, France, March 4-7, 2013.

[4] Ferroni, P., et al., Modeling and Validation of Sodium Plugging for Heat Exchangers in Sodium-cooled Fast Reactor Systems. United States: N. p., Web. doi:10.2172/1259680, 2016.

[5] Saito, N., Liao, C., and Tsuruda, T., "Ignition and Extinguishment of Sodium Fires in Air Diluted by Nitrogen", Proceedings of the $5^{\text {th }}$ AOSFST, p. 285-294, 2001. 


\section{Argonne}

Nuclear Engineering Division

Argonne National Laboratory

9700 South Cass Avenue, Bldg. 208

Argonne, IL 60439

www.anl.gov 